\title{
Seedling establishment of epiphytic orchids in forests and coffee plantations in Central Veracruz, Mexico
}

\author{
Susanne Scheffknecht*, Manuela Winkler*, Karl Hülber†, Martín Mata Rosasł and Peter Hietz*,1 \\ * Institute of Botany, Department of Integrative Biology, University of Natural Resources and Applied Life Sciences (Boku), Gregor-Mendel-Str. 33, 1180 Vienna, Austria \\ $\dagger$ VINCA - Vienna Institute for Nature Conservation \& Analyses, Giessergasse 6/7, 1090 Vienna, Austria \\ $\ddagger$ Instituto de Ecología, A.C., km. 2.5 carretera antigua a Coatepec 351, Congregación El Haya, Xalapa 91070, Veracruz, México \\ (Accepted 27 August 2009)
}

\begin{abstract}
The distribution of epiphytes differs between branches within tree crowns as well as within habitats. Where the original forests have been lost, shade coffee plantations can be important refuges for epiphytes, but are not suitable for all species. To understand what affects habitat quality, we transplanted 1440 seedlings each of two orchids, one, Lycaste aromatica, restricted to forests, the other, Jacquiniella teretifolia, common on trees in coffee plantations and in forests. Seedling mortality and growth were compared between three forests, three young and three old coffee plantations to test for differences between habitats and to analyse which habitat features affect growth and mortality. In J. teretifolia there was no clear pattern of habitat effect on mortality $\left(c .0 .08 \mathrm{mo}^{-1}\right)$, but the production of new shoots was higher in coffee plantations than in forests. In L. aromatica, growth rates as well as seedling mortality increased over time. During the last census growth rates in forests $\left(1.8 \mathrm{~mm} \mathrm{mo}^{-1}\right)$ were significantly higher than in old $\left(0.9 \mathrm{~mm} \mathrm{mo}^{-1}\right)$ and young $\left(1.2 \mathrm{~mm} \mathrm{mo}^{-1}\right)$ coffee plantations, and seedling mortality was about four times higher in old $\left(0.10 \mathrm{mo}^{-1}\right)$ and young $\left(0.11 \mathrm{mo}^{-1}\right)$ coffee plantations than in forests $\left(0.025 \mathrm{mo}^{-1}\right)$, which may explain the natural absence of $L$. aromatica from coffee plantations. Mortality in L. aromatica at individual sites was negatively correlated with bryophyte cover on branches (Pearson $r=-0.75)$ and positively with lichen cover $(r=0.70)$ and canopy openness $(r=0.75)$. Branch cover with non-vascular epiphytes, whether directly responsible by improving the water supply to epiphytes or indicative of differences in microclimate, may be a useful indicator of suitable habitats for vascular epiphytes.
\end{abstract}

Key Words: Coffee plantation, epiphyte, growth rate, mortality rate, Orchidaceae, transplantation experiment, tropical montane forest

\section{INTRODUCTION}

The composition of epiphyte communities differs between forest types (Hietz \& Hietz-Seifert 1995), between natural forests and anthropogenic vegetation (Flores-Palacios \& García-Franco 2008, Hietz 2005), and also within a tree where species are often observed to prefer different microhabitats (Zotz 2007). As with other plants, preference of any habitat can be the result of differences in seed dispersal, germination, growth, survival or reproduction, which can be affected by biotic or abiotic factors.

In secondary habitats, the presence or absence of epiphyte species is determined by two processes. At first,

\footnotetext{
${ }^{1}$ Corresponding author. Email: peter.hietz@boku.ac.at
}

seed dispersal can limit the colonization of new trees by epiphytes if external seed sources are scarce or far away (Cascante-Marín et al. 2009). Dispersal can also affect within-tree distribution of epiphytes with different dispersal modes (Fischer \& Araujo 1995), but we consider it unlikely to be responsible for habitat selection in epiphytes with very similar diaspores and thus similar dispersal, such as orchids. After successful seed dispersal and germination, plants require a suitable environment for survival, growth and reproduction, which may not be found in secondary habitats. Though biotic interaction may also play a role, epiphytes are thought to be limited mainly by abiotic constraints, particularly water availability (Zotz et al. 2001). Microclimate, and thus abiotic stress, differs between habitats as well as between branches within a tree (Cardelús \& Chazdon 2005), and other characteristics of branches such as bark 
Table 1. Elevation and mean tree density of habitat (each with three replicates) and size of trees used for transplanting juvenile orchids. Different lower-case letters indicate significant differences among habitats (nested ANOVA and multiple comparisons of linear contrasts by the Scheffé method, $\mathrm{P}<0.05)$.

\begin{tabular}{|c|c|c|c|c|}
\hline & \multirow[b]{2}{*}{ Altitude (m asl) } & \multirow[b]{2}{*}{ Tree density $\left(\mathrm{ha}^{-1}\right)$} & \multicolumn{2}{|c|}{ Experimental trees } \\
\hline & & & Height $(\mathrm{m} ;$ mean \pm SD) & $\mathrm{dbh}(\mathrm{cm} ;$ mean $\pm \mathrm{SD})$ \\
\hline Forest & 1350 & 605 & $19.4 \pm 2.8^{\mathrm{a}}$ & $59.0 \pm 25.1^{\mathrm{a}}$ \\
\hline Old plantation & $1200-1300$ & 133 & $18.5 \pm 2.9^{\mathrm{a}}$ & $61.4 \pm 15.9^{\mathrm{a}}$ \\
\hline Young plantations & $1250-1300$ & 233 & $9.3 \pm 1.5^{b}$ & $27.2 \pm 4.6^{\mathrm{b}}$ \\
\hline
\end{tabular}

roughness and the cover by cryptogams may affect vascular epiphytes growing on it (Callaway et al. 2002).

The seedling stage is one of the most vulnerable periods in the life cycle of many plants, including epiphytes (Zotz \& Hietz 2001) and may constitute the bottleneck for colonizing new sites. Seedling performance is therefore often used to compare the suitability of habitats for different species and to understand what habitat characteristics determine habitat selection (Pearson et al. 2003). A few studies have analysed the survival of transplanted epiphyte seedlings, either within the canopy (Winkler et al. 2005, Zotz \& Vollrath 2002) or between habitats but without a replication of habitat types (Cascante-Marín et al. 2008).

Understanding what limits a species from any habitat and particularly secondary habitats is also of importance for conservation. For instance, shade trees in coffee plantations are an important refuge for many groups of organisms (Armbrecht et al. 2005, Gordon et al. 2007, Perfecto et al. 1996) including epiphytes in areas where little natural forest remains (Hietz 2005, Sosa \& Platas 1998). However, not all epiphytes are found on shade trees and not all coffee plantations are equally suitable (Hietz 2005). Understanding why some are able to colonize plantations whereas others cannot, or are found in some types of plantations but not in others, may help to design 'epiphyte friendly' or generally diversityconserving ways to grow coffee and to manage the cultural landscape.

Asking what affects the suitability of different habitats and different branches within a tree, we analysed seedling mortality and growth of two species of epiphytic orchids, one, Jacquiniella teretifolia, a common colonizer of secondary vegetation, the other, Lycaste aromatica, mostly limited to natural forests. Plants were transplanted to forests, coffee plantations with old and plantations with young shade trees. In addition to the comparison of habitats we asked which habitat features affect growth and survival of plants. We hypothesize that seedlings of the forest species have low growth and high mortality rates in coffee plantations, which may restrict this species to closed forests. Lycaste aromatica is also found in substantially drier forests at lower altitudes in the area, and in any forest is found mostly on larger branches (Hietz \& Hietz-Seifert 1995). We therefore hypothesize that the survival of L. aromatica is related to branch size, bryophyte cover or the thickness of any substrate on the branch, all of which may affect the branch's water-holding capacity. In contrast, seedlings of the generalist J. teretifolia are expected to grow in plantations as well as or better than in forests and have higher growth rates on exposed branches receiving more light. Finally, we expected to find the highest mortality in the dry season in both species.

\section{MATERIALS AND METHODS}

\section{Study area and sites}

Field work was carried out between October 2006 and February 2008 in the vicinity of Coatepec $\left(19^{\circ} 27^{\prime} \mathrm{N}\right.$, $\left.96^{\circ} 57^{\prime} \mathrm{W}\right)$, a centre of coffee cultivation in Central Veracruz, Mexico, at altitudes between 1200 and $1350 \mathrm{~m}$ asl. The climate is humid temperate with a comparatively dry and cool season from October/November to March, a dry and warm season from April to May and humid and warm season from June to September/October. Mean annual temperature in Coatepec is $19.5^{\circ} \mathrm{C}$ and precipitation is $1765 \mathrm{~mm} \mathrm{y}^{-1}$ (Comisión Nacional de Agua http://smn.cna.gob.mx/productos/normales/ estacion/ver/NORMAL30026.TXT).

The study area is in the lower elevational range of the humid montane forest. The natural vegetation is mostly reduced to forest fragments in locations difficult to access such as steep slopes, crests and canyons. Agricultural landscape is formed by coffee plantations, fields (mostly sugar cane) and pastures.

Three habitats were included in the study and three individual sites selected for each habitat (Table 1). We transplanted seedlings to forests and two types of coffee plantations, one with old shade trees and the other with young shade trees. Size and species of all trees $>10$ $\mathrm{cm}$ diameter at breast height $(\mathrm{dbh})$ were recorded on a $20 \times 20$-m plot within each study site. All forests were dominated by Quercus spp., all plantations by Inga spp.

\section{Study species}

Lycaste aromatica (Graham ex Hook.) Lindl. has ovate pseudobulbs up to $7 \mathrm{~cm}$ tall with large plicate leaves up to 
$60 \mathrm{~cm}$ long, which are shed in the dry season. This species was almost exclusively found in natural forests, in some places with very small populations, in others with several hundred individuals. Jacquiniella teretifolia (Sw.) Britt. \& P. Wilson is a caespitose erect bulbless plant up to 30 $\mathrm{cm}$ tall with linear fleshy distichous leaves regularly distributed along the stems. It is a very common orchid in the area and found in forests as well as other woody vegetation, including coffee shade trees.

\section{Experimental design}

Seeds were collected from plants growing in the region, surface sterilized, and cultivated in sterile jars on $25 \mathrm{ml}$ of half-strength Murashige and Skoog medium (Murashige \& Skoog 1962) plus $30 \mathrm{~g} \mathrm{l}^{-1}$ sucrose adjusted to $\mathrm{pH} 5$. Cultures were incubated at $25^{\circ} \mathrm{C} \pm 1{ }^{\circ} \mathrm{C}$, under a 16 -h photoperiod provided by cool-white fluorescent lamps (50 $\mu \mathrm{mol} \mathrm{m} \mathrm{m}^{-2} \mathrm{~s}^{-1}$ ). After $9 \mathrm{mo}$ the seedlings were transferred to propagation trays with a mix of pine bark:oak charcoal:pumice (3:1:1) and placed in a shadehouse. The trays were covered with plastic translucent lids during the first $30 \mathrm{~d}$, then the lids were progressively lifted for the plants to adapt to ambient relative humidity, and plants were irrigated twice weekly with rainwater. After 3 mo in the shade-house seedlings were transplanted to the study sites.

At each of the nine study sites we selected 16 trees that reached the upper canopy from which eight trees were randomly chosen. On each tree, two branches in the upper and two in the lower part of the crown were selected for transplantation. We measured height and dbh of each experimental tree. For each branch section carrying transplanted seedlings height above ground, inclination, diameter and canopy openness above the branch (using a spherical densiometer, Ben Meadows, Janesville WI, USA) were measured. The percentage of the upper branch surface covered by bryophytes, lichens, vascular epiphytes or bare bark, as well as the thickness of this substrate were estimated.

To study differences in microclimate, temperature and relative humidity were recorded every $10 \mathrm{~min}$ with three HoboPro (Onest, Pocasset, MA, USA) and two TinytagPlus (Tinytag, Chichester, UK) dataloggers. Dataloggers were exposed at c. 2/3 of the canopy height between September 2006 and July 2007 and rotated between sites every 1 or 2 mo.

In total, 1440 seedlings of each species ( 5 seedlings per branch $\times 4$ branches $\times 8$ trees $\times 3$ sites $\times 3$ habitats) were transplanted by climbing trees with single-rope technique and tying their roots with strips of elastic synthetic gauze to the branches. Labels with seedling number were pinned next to their position.
In L. aromatica the height of each pseudobulb, in J. teretifolia the height of each stem from the base of the stem to the tip of the uppermost leaf were measured to the nearest $\mathrm{mm}$. Throughout the study we used shoot length as a measure of plant size. While we define both pseudobulbs and stems as shoots and the sum of all shoot lengths of an individual as plant size. Plant size was measured at the beginning of the transplantation experiment in October 2006, and again in March 2007, August 2007 and February 2008. Initial size (mean \pm SD) was $65.7 \pm 25.8 \mathrm{~mm}$ for J. teretifolia and $22.9 \pm 9.5 \mathrm{~mm}$ for L. aromatica with an average of $2.1 \pm 0.8$ and $2.1 \pm$ 1.3 shoots, respectively. At each census seedling mortality and size was noted.

\section{Statistical analysis}

Monthly growth rates per seedling were calculated as the increment of plant size divided by the months passed since the last census. Monthly mortality rates (m) were calculated at branch level using the following equation (Sheil et al. 1995):

$$
m=1-\left(1-\left(\frac{\left(M_{t 1}\right)}{\left(A_{t 1}+M_{t 1}\right)}\right)\right)^{\left(\frac{1}{(t 1-t 0)}\right)}
$$

where $M_{t 1}$ is the number of plants dead at census time $t_{1}$, $A_{t 1}$ the number of plants alive at census time $\mathrm{t}_{1}$ and $\mathrm{t}_{1}-$ $t_{0}$ the time between censuses. A few plants that were missing rather than found dead were assumed to have dropped and were eliminated from the analysis.

Growth and $\log (m+1)$-transformed mortality rates were analysed using a nested analysis of variance (ANOVA) with habitat as main fixed factor and site and tree as random factors, each fully nested in the respectively higher level. When the response differed significantly between habitats pairwise post hoc comparisons for linear contrasts were conducted using the Scheffé test.

Growth and mortality rates between the upper and lower branches were compared with paired t-tests with growth/mortality averaged for two branches of a tree. Influence of various branch parameters on growth and mortality rates of the study species were analysed using simple and multiple linear regressions.

Statistical analyses were performed using R 2.5.0 (R Development Core Team, http://www.R-project.org).

\section{RESULTS}

\section{Growth}

Temperature and precipitation during the experiment are shown in Figure 1a. During the first 6 mo after transplantation (October 2006-March 2007) the 

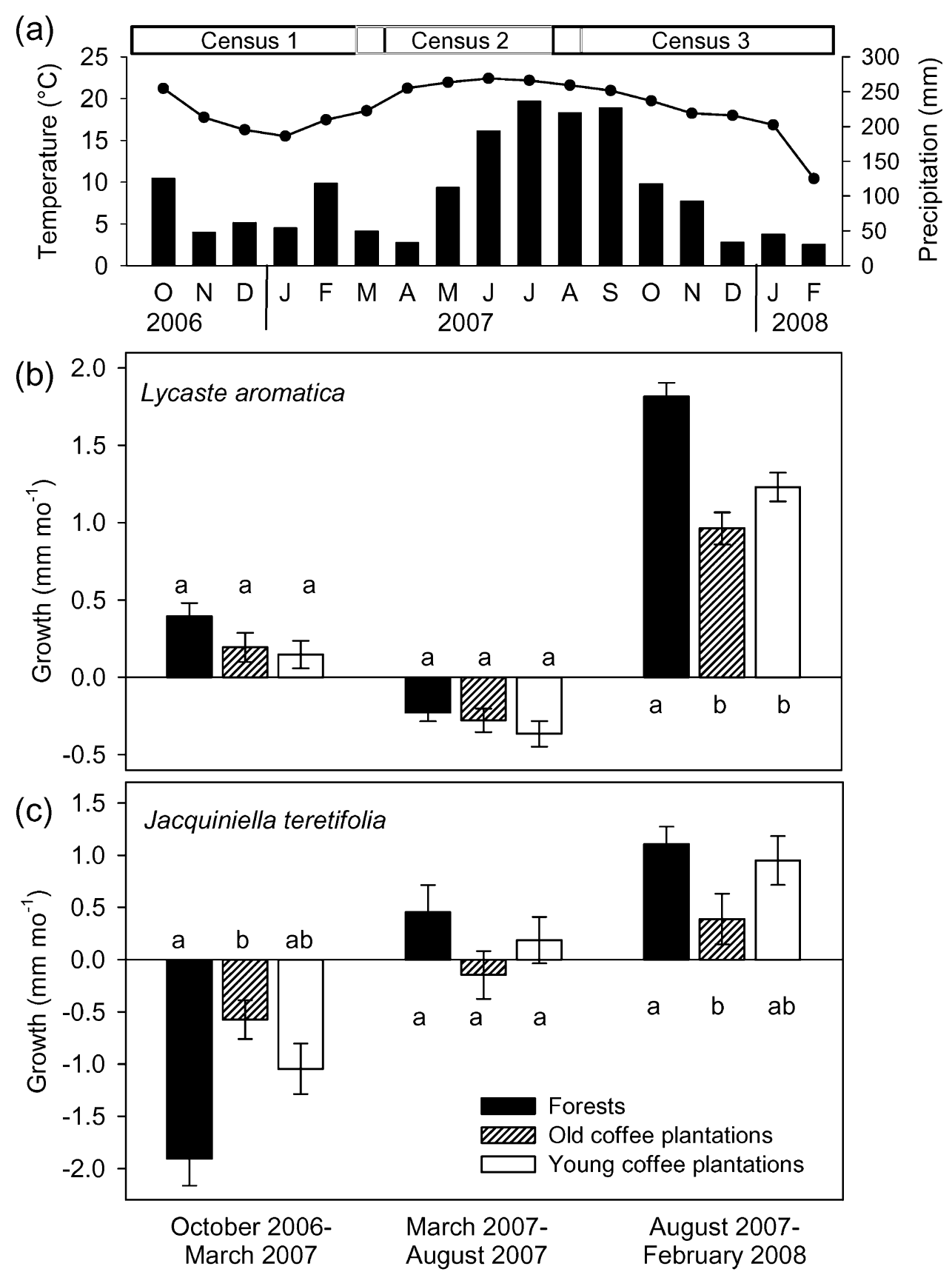

Census interval

Figure 1. Climate and monthly growth rates of seedlings of two orchid species transplanted to trees in three different habitats during three census intervals. Monthly mean temperature (line) and total precipitation (bars) in the area during the observation period. Bars on top indicate the census periods (a). Growth rates of Lycaste aromatica (b), and Jacquiniella teretifolia (c). Error bars indicate standard error. Different lower-case letters indicate significant differences (nested ANOVA and multiple comparisons of linear contrasts by the Scheffé test, $\mathrm{P}<0.05$ ).

monthly growth rate of $L$. aromatica seedlings was highest in forests and lowest in young coffee plantations (Figure 1b) although the difference was not significant $\left(\mathrm{F}_{2,1293}=2.19, \mathrm{P}=0.11\right)$. From March 2007 to August 2007 seedling growth rates were negative as shoots of many seedlings died. Habitat had no significant effect $\left(\mathrm{F}_{2,1101}=0.95, \mathrm{P}=0.39\right)$ on growth, but in coffee plantations the reduction in shoot numbers was significantly higher than in forests $\left(\mathrm{F}_{2,1052}=10.9\right.$, $\mathrm{P}<0.001$ ). Between August 2007 and February 2008 seedling growth rates increased strongly. Growth rates varied significantly between habitats $\left(\mathrm{F}_{2.916}=22.74\right.$, $\mathrm{P}<0.001)$ and were higher in forests than in coffee plantations. 


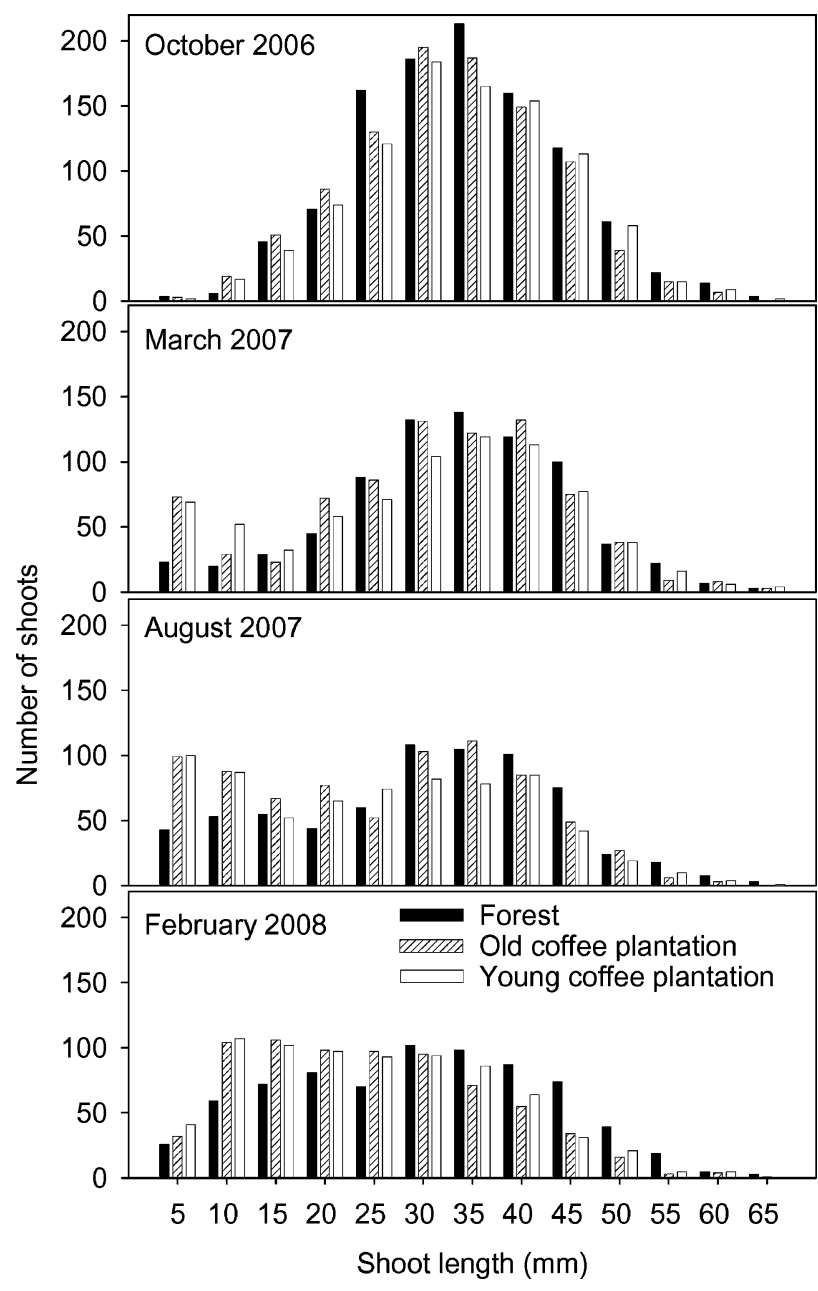

Figure 2. Change in the frequency of shoot size classes of Jacquiniella teretifolia seedlings transplanted to trees in three different habitats after transplantation in October 2006.

In J. teretifolia initial growth was negative because shoots were lost or died at the apex. Habitat had a significant effect on growth $\left(\mathrm{F}_{2,1053}=9.13, \mathrm{P}<0.001\right.$, Figure 1c) with the strongest reduction in size in forests and least in old coffee plantations. Between March and August 2007 growth was low but positive (except for old plantations) with no significant habitat effect $\left(\mathrm{F}_{2,746}=\right.$ $1.69, \mathrm{P}=0.18)$. In the last interval growth was generally higher, differed between habitats $\left(\mathrm{F}_{2,661}=3.23, \mathrm{P}<\right.$ $0.05)$ and was significantly higher in forests than in old plantations.

The fact that the initial decline in size was highest in forests and least in old plantations but later positive growth was highest in forests and lowest in old plantations is explained by changes in shoot size and numbers (Figure 2). At the first census, all plants had lost shoots in most size classes, but plants in coffee plantations developed more new shoots than in forests. Subsequently,

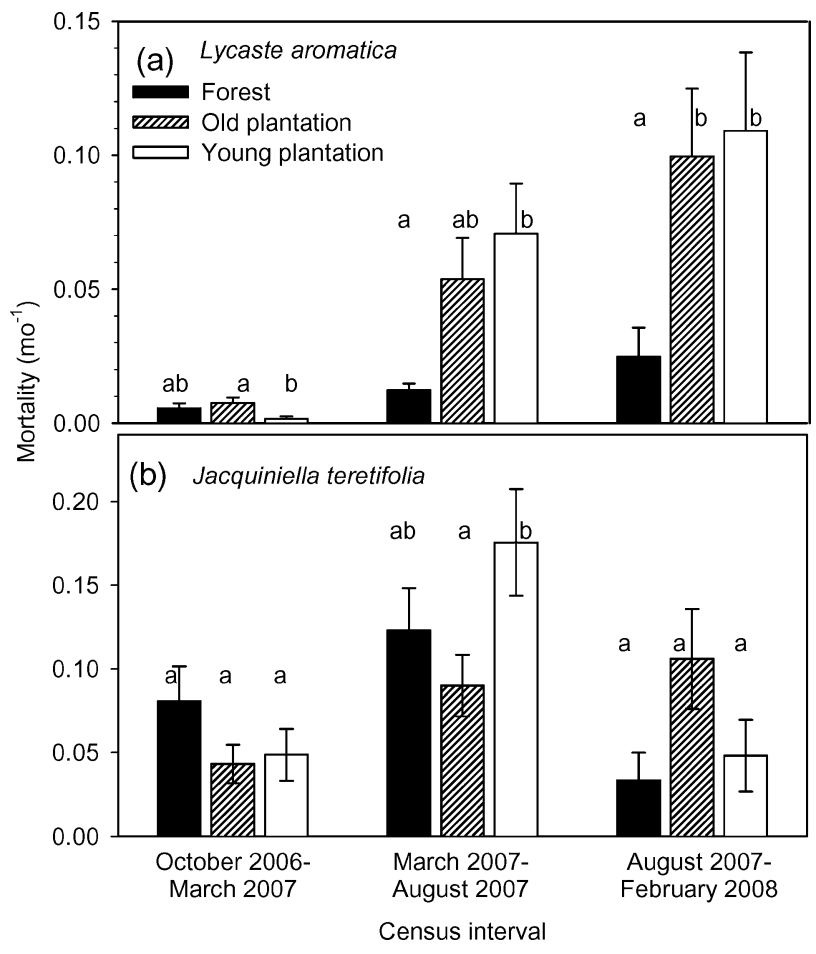

Figure 3. Mortality rates of seedlings of epiphytic orchids transplanted to three different habitats. Lycaste aromatica (a), and Jacquiniella teretifolia (b). Error bars indicate standard error. Different lower-case letters indicate significant differences (nested ANOVA and multiple comparisons of linear contrasts by the Scheffé test, $\mathrm{P}<0.05)$.

plants in plantations continued to grow more new shoots, but plants in forests lost fewer large shoots.

Root growth was not measured, but in both species the original roots did not attach themselves to the new branches but withered and died. New roots began to emerge about 6 mo after transplantation in J. teretifolia and after about 12 mo in L. aromatica. Root growth in both species began first in coffee plantations, and later in forests.

\section{Mortality}

During the first 6 mo after transplantation (October 2006-March 2007) mortality in L. aromatica was low and showed nearly significant differences between habitats $\left(\mathrm{F}_{2,267}=3.01, \mathrm{P}=0.05\right.$, Figure 3a) with the lowest mortality in young and the highest in old coffee plantations. From March to August 2007 monthly mortality rates increased and differed significantly between habitats $\left(\mathrm{F}_{2,267}=6.17, \mathrm{P}<0.01\right)$ with mortality rate in young coffee plantations being almost six times higher than in forests. Between August and February 2008 mortality increased again and differed between habitats $\left(\mathrm{F}_{2,261}=4.67, \mathrm{P}=0.01\right)$ being about four times higher in young plantations than in forests. 


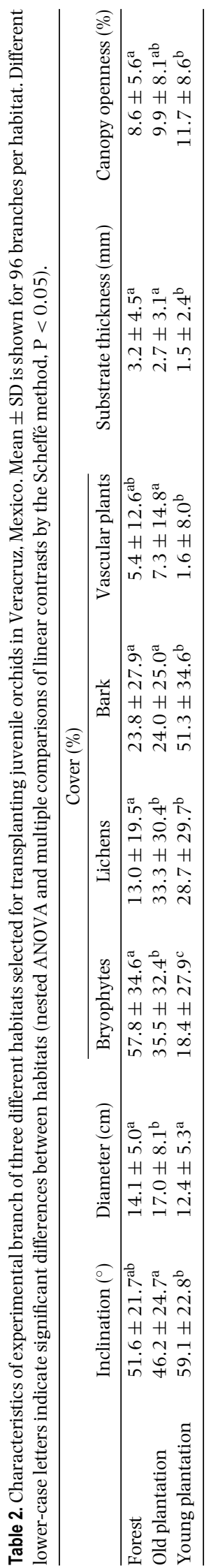

In J. teretifolia mortality was generally higher than in L. aromatica, particularly during the first months after transplantation when there was no significant habitat effect on J. teretifolia mortality $\left(\mathrm{F}_{2.266}=1.60, \mathrm{P}=0.21\right.$, Figure 3b). Between March and August 2008 mortality increased in all habitats with a significant habitat effect $\left(\mathrm{F}_{2,258}=3.16, \mathrm{P}<0.05\right.$; Figure $\left.3 \mathrm{~b}\right)$ and higher mortality in young than in old plantations. During the last period mortality was somewhat lower again with a nearly significant habitat effect $\left(\mathrm{F}_{2,237}=2.97, \mathrm{P}=0.05\right)$.

\section{Effect of branch characteristics and climate}

In both species growth was faster on upper branches than on lower branches in forests and old coffee plantations and faster on lower branches in young plantations (Figure 4), although we detected a significant difference only for $L$. aromatica in the young plantations (paired t-test $\mathrm{t}=3.76$, $\mathrm{P}<0.01$ ). Mortality was mostly lower on the upper branches in forests and old plantations but higher in young plantations, though none of these differences was significant. When growth and mortality on individual branches were tested, none of the branch parameters (Table 2) had a significant effect (data not shown).

Branch parameters differed significantly between habitats with selected branches in forests having higher bryophyte and lower lichen cover than plantations, in young plantations having more bare bark area than in forests or old plantations and lower substrate thickness and higher canopy openness than in forests, and in old plantations having higher branch diameter than in forests and young plantations (Table 2). Lycaste aromatica mortality was negatively correlated with mean bryophyte cover per site and positively with lichen cover and canopy openness (Table 3).

Air temperature and relative humidity recorded at individual sites over most of the time of the experiment were not related to growth or mortality (data not shown).

\section{DISCUSSION}

Transplantation experiments are simple tools to test for environmental effects on plants, and epiphytes are easier to transplant than most ground-rooting plants. Compared with our artificially propagated plants, local field-grown plants (Zotz \& Vollrath 2002) likely suffer less transplantation stress, and using entire epiphyte mats resulted in no increased mortality (Nadkarni \& Solano 2002). For our study sampling a high number of rare orchids from the field was not an option, thus we relied on artificial propagation. Transplantation stress was likely to have had an effect on initial growth and mortality, which is obvious in J. teretifolia where initial growth was 


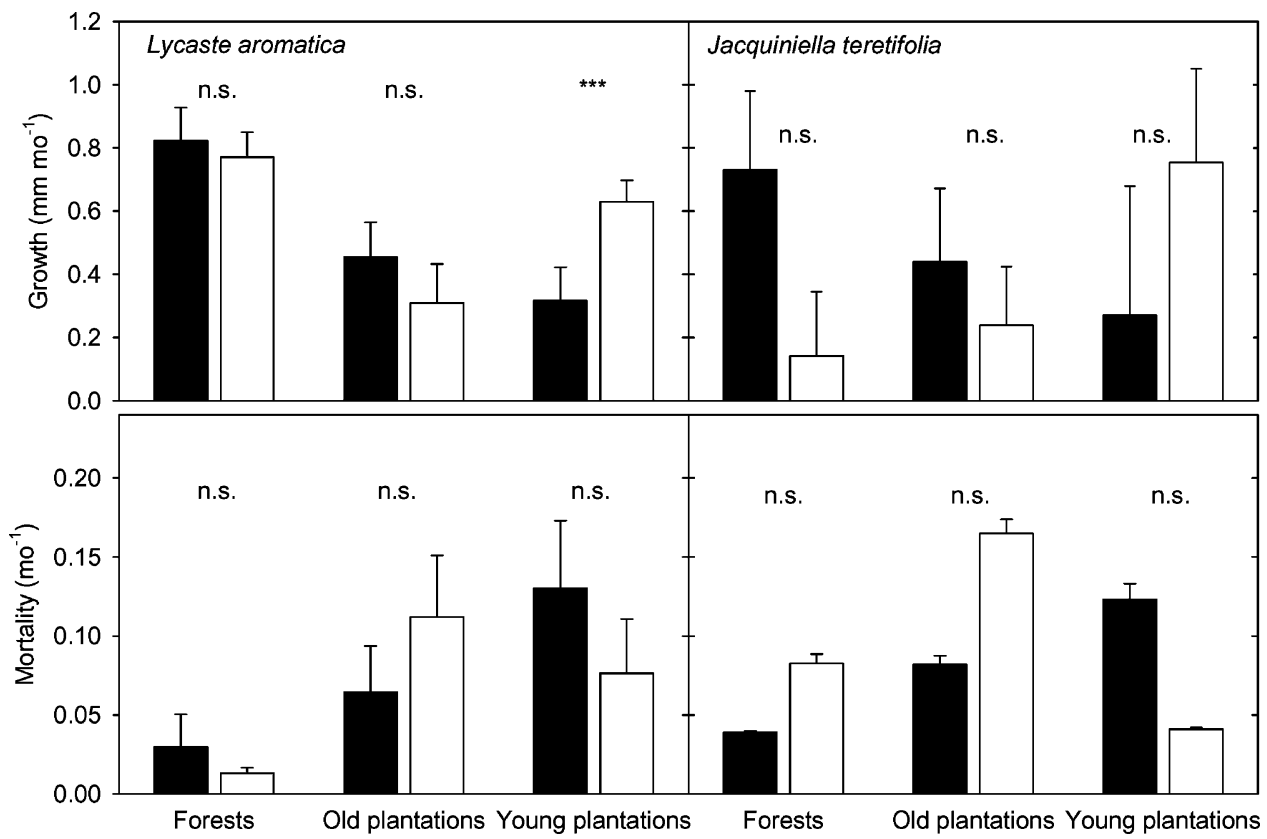

Figure 4. Growth (upper graphs) and mortality (lower graphs) of epiphytic Lycaste aromatica (left) and Jacquiniella teretifolia (right) seedlings transplanted to branches in the upper (black bars) and lower (empty bars) crown on trees in three different habitats. Error bars indicate standard error, ${ }^{* *}$ indicates significant difference (paired t-test, $\mathrm{P}<0.01$ ).

negative. During the last census interval the mortality rates of transplanted seedlings in forests $\left(0.025 \mathrm{mo}^{-1}\right)$, which were $c .2 .5 \mathrm{y}$ old, were in the range of juvenile plants beyond the seedling stage in the field at the Parque site (average mortality over 3 y was 0.014 and $0.017 \mathrm{mo}^{-1}$ for L. aromatica and J. teretifolia respectively; Winkler 2005), so apparently after some adaptation the transplanted plants reflect the situation in the field well. Mean natural growth rates of up to $c$. 2-y-old seedlings at the Parque site were $0.7 \mathrm{~mm} \mathrm{mo}^{-1}\left(\mathrm{SD}=0.8 \mathrm{~mm} \mathrm{mo}^{-1}, \mathrm{n}=84\right)$ and 1.1 $\mathrm{mm} \mathrm{mo}^{-1}\left(\mathrm{SD}=0.5 \mathrm{~mm} \mathrm{mo}^{-1}, \mathrm{n}=11\right)$ for J. teretifolia and L. aromatica, respectively (M. Winkler unpubl. data).

After very low or even negative growth rate during the first two census intervals, growth rates of L. aromatica seedlings were higher in forests than in coffee plantations. During the last period the difference between forests and coffee plantations was especially pronounced with growth rates in forests about $60 \%$ higher than in plantations and mortality dramatically higher in plantations than in forests. Seedling mortality in L. aromatica increased over time even though the final interval overlaps more with the wet season than the second interval, and other studies found that seedling mortality of epiphytes declines with increasing size (Benzing 1978, Benzing 1981, Hietz 1997, Winkler 2005). Apparently, death in L. aromatica is a drawn-out process and individuals that for whatever reason do not achieve a positive growth balance die slowly as the reserves in their pseudobulbs are exhausted. The 1-y-old seedlings transplanted were grown under near-optimum conditions and were certainly larger than seedlings would be at this age in the field. Considering transplantation stress, the fact that roots were initially

Table 3. Correlations (Pearson $r$ ) between branch characteristics of nine sites (three forests, three coffee plantations with old and three with young shade trees) and growth and mortality of epiphytic Jacquiniella teretifolia and Lycaste aromatica. Significant correlations $(\mathrm{P}<0.05)$ are printed in bold.

\begin{tabular}{|c|c|c|c|c|}
\hline \multirow[b]{2}{*}{ Correlations } & \multicolumn{2}{|c|}{ J. teretifolia } & \multicolumn{2}{|c|}{ L. aromatica } \\
\hline & Mortality & Growth & Mortality & Growth \\
\hline Bryophytes & 0.077 & 0.571 & -0.751 & 0.583 \\
\hline Lichens & 0.045 & -0.658 & 0.704 & -0.573 \\
\hline Bare bark & -0.170 & -0.243 & 0.419 & -0.231 \\
\hline Vascular plants & 0.121 & 0.165 & -0.076 & -0.227 \\
\hline Substrate thickness & 0.143 & 0.225 & -0.001 & -0.069 \\
\hline Canopy openness & -0.216 & -0.657 & 0.748 & -0.352 \\
\hline Inclination & -0.274 & 0.437 & -0.258 & 0.039 \\
\hline Diameter & 0.207 & -0.336 & 0.236 & -0.354 \\
\hline
\end{tabular}


not attached to the substrate and at least some habitats were likely unsuitable for the species, mortality was surprisingly low and only $15 \%, 35 \%$ and $32 \%$ had died after 17 mo in forests, old and young plantations, respectively. In J. teretifolia, the $43 \%, 44 \%$ and $45 \%$ of seedlings died in forests, old and young plantations, respectively. If final seedling mortality in L. aromatica is several-fold higher in coffee plantations (about $10 \%$ $\mathrm{mo}^{-1}$ ) than in forests, this likely excludes the species from establishing in coffee plantations.

Disturbed forests and open vegetation are generally drier than the forest interior (Laurance 2004), but the difference between our study sites is subtle and neither mortality nor growth were related to temperature or air humidity. Also, L. aromatica occurs in much drier oak forests at lower elevations in the area (Hietz \& HietzSeifert 1995) and mostly grows on larger branches in the lower canopy (Winkler \& Hietz 2001), so the hypothesis was that branch parameters play a bigger role in this species. Branches of experimental trees in old plantations were even somewhat thicker than in forests and similar in rugosity and substrate thickness, but had lower bryophyte and higher lichen cover. Though the within-site effect of branch parameters was not significant, bryophyte cover had a positive effect on $L$. aromatica survival and growth when individual sites were compared. Lichens typically cover branches in more exposed conditions and drier sites and lichens and canopy openness were negatively correlated with L. aromatica survival. Bryophytes can improve the water-holding capacity of branches (Pypker et al. 2006) and for epiphytic orchids, which, unlike bromeliads, absorb water primarily through their roots, the substrate on the branch may be more important than the microclimate in defining suitable habitats.

For J. teretifolia seedlings we predicted growth rates to be equal or higher in coffee plantations than in forests. This prediction holds true only for the first 6 mo when fewer shoots died after transplanting in plantations. Later shoot growth, measured as the difference in length of all shoots, tended to be higher in forests but the number of shoots was much higher in coffee plantations, and higher in young than in old plantations, with no clear pattern in mortality. An analysis of shoot size distribution shows that while more of the larger shoots present at the time of transplantation died in coffee plantations, plants in plantations at the same time produced more new shoots. Thus it appears that shoots produced before transplantation may have been adapted to higher humidity and were not completely acclimatized, but the potential for growth is higher in coffee plantations. Although the death of many shoots following transplantation in J. teretifolia confounds the outcome, we interpret the significantly higher production of new shoots in coffee plantations as supporting our initial hypothesis. In all three old coffee plantations included in the study J. teretifolia is naturally abundant (but found only in two young plantations and one forest). A detailed study at La Orduña found high densities of over 800 plants ha $^{-1}$ and a great abundance of small and young plants, showing that conditions were adequate for seed germination and establishment (Solis-Montero et al. 2005).

Some other studies have tried to correlate the performance of epiphyte seedling with distribution. Zotz \& Vollrath (2002) found no effect of position within the tree crown on seedling mortality of three bromeliad that could explain their within-crown distribution, but for a hemiepiphytic strangling fig (Ficus stupenda) the preference of knotholes concurred with higher seedling survival in these microsites with substantially higher moisture retention (Laman 1995). In an attempt to explain different colonization of secondary forests by some species, seedling survival and growth were higher in early successional forests than in mature forest in Costa Rica, but this was not related to habitat preference and thus does not explain species distribution (Cascante Marín et al. 2008). By contrast, in the area of an Ecuadorean moist montane forest, survival rates of two xeric epiphytes were higher than those of two mesic species on isolated trees (Werner \& Gradstein 2008), but sample numbers (5-19 individuals) were low.

One reason for the high variance found in epiphyte performance in many studies may be the difficulty of accurately describing the relevant micro-environment for each plant. For instance, if branches were described as having an area of $40 \%$ covered by bryophyte, this could effectively mean that two plants are rooting in bryophyte mats but the other three are not. Also, chance or stochastic processes may play a more important role in the fate of individual epiphytes than generally recognized, complicating attempts to analyse the effect of environmental parameters. For orchids with minute seeds, this starts with the chance if and where exactly on a branch a seed lands, and ends with the danger of falling to the ground with a breaking branch.

This does not exclude alternative explanations. Substantial differences in dispersal characteristics are unlikely in orchids, all of which have minute, dustlike and wind-dispersed seeds. However, orchids require a mycorrhizal partner to germinate, some orchid mycorrhiza can be quite specific (McCormick et al. 2006), and the presence or absence of fungi may limit orchids to certain substrates or habitats (Bayman et al. 1997, Tremblay et al. 1998). Unfortunately, studying orchid mycorrhizal associations in the field is often difficult and our germination trials with epiphytic orchids failed.

In Central America many montane forests have been replaced with coffee plantations. Where few natural forests are left, traditional coffee plantations with large shade trees play an important role in conserving biodiversity (Perfecto et al. 1996), but are not a suitable habitat for all species (Hietz 2005). In our study, 
seedling mortality during the last interval, which was about $10 \% \mathrm{mo}^{-1}$, is sufficient to explain the absence of L. aromatica from coffee plantations and was correlated with the low bryophyte cover on branches in coffee plantations. Bryophytes may be directly responsible by improving the water supply or indicative of differences in microclimate and could thus be useful indicators of habitat quality for vascular epiphytes. Understanding what permits individual species to thrive and identifying suitable habitats is important to manage coffee plantations as well as other non-natural ecosystems to maximize their value for conserving biodiversity.

\section{ACKNOWLEDGEMENTS}

We thank Alejandro Hernández-Sánchez, Luis Tlaxcalteco Tepo and Adriana Hernández Rojas for help in the field, Rosario Julieta Baltasar for propagating the seedlings, José García-Franco and the Instituto deEcología in Xalapa for general support and valuable discussions and all plantation owners for permitting this work. Two anonymous reviewers provided helpful comments on a previous version of the manuscript. This research was funded by the Austrian Science Fund (FWF grant $\mathrm{P} 17875)$ to $\mathrm{PH}$.

\section{LITERATURE CITED}

ARMBRECHT, I., RIVERA, L. \& PERFECTO, I. 2005. Reduced diversity and complexity in the leaf-litter ant assemblage of Colombian coffee plantations. Conservation Biology 19;897-907.

BAYMAN, P., LEBRON, L. L., TREMBLAY, R. L. \& LODGE, D. J. 1997. Variation in endophytic fungi from roots and leaves of Lepanthes (Orchidaceae). New Phytologist 135;143-149.

BENZING, D. H. 1978. Germination and early establishment of Tillandsia circinnata Schlecht. (Bromeliaceae) on some of its hosts and other supports in southern Florida. Selbyana 5:95-106.

BENZING, D. H. 1981. The population dynamics of Tillandsia circinnata (Bromeliaceae): cypress crown colonies in southern Florida. Selbyana 5:256-263.

CALLAWAY, R. M., REINHART, K. O., MOORE, G. W., MOORE, D. J. \& PENNINGS, S. C. 2002. Epiphyte host preferences and host traits: mechanisms for species-specific interactions. Oecologia 132:221230.

CARDELÚS, C. L. \& CHAZDON, R. L. 2005. Inner-crown microenvironments of two emergent tree species in a lowland wet forest. Biotropica 37:238-244.

CASCANTE-MARÍN, A., WOLF, J. H. D., OOSTERMEIJER, J. G. B. \& DEN NIJS, J. C. M. 2008. Establishment of epiphytic bromeliads in successional tropical premontane forests in Costa Rica. Biotropica 40:441-448.

CASCANTE-MARÍN, A., VON MEIJENFELDT, N., DE LEEUW, H. M. H., WOLF, J. H. D., OOSTERMEIJER, J. G. B. \& DEN NIJS, J. C. M. 2009. Dispersal limitation in epiphytic bromeliad communities in a Costa
Rican fragmented montane landscape. Journal of Tropical Ecology 25:63-73.

FISCHER, E. A. \& ARAUJO, A. C. 1995. Spatial organization of a bromeliad community in the Atlantic rainforest, south-eastern Brazil. Journal of Tropical Ecology 11:559-567.

FLORES-PALACIOS, A. \& GARCÍA-FRANCO, J. 2008. Habitat isolation changes the beta diversity of the vascular epiphyte community in lower montane forest, Veracruz, Mexico. Biodiversity and Conservation 17:191-207.

GORDON, C., MANSON, R., SUNDBERG, J. \& CRUZ-ANGÓN, A. 2007. Biodiversity, profitability, and vegetation structure in a Mexican coffee agroecosystem. Agriculture, Ecosystems \& Environment 118:256-266.

HIETZ, P. 1997. Population dynamics of epiphytes in a Mexican humid montane forest. Journal of Ecology 85:767-775.

HIETZ, P. 2005. Conservation of vascular epiphyte diversity in Mexican coffee plantations. Conservation Biology 19:391-399.

HIETZ, P. \& HIETZ-SEIFERT, U. 1995. Composition and ecology of vascular epiphyte communities along an altitudinal gradient in central Veracruz, Mexico. Journal of Vegetation Science 6:487498.

LAMAN, T. G. 1995. Ficus stupenda germination and seedling establishment in a Bornean rain forest canopy. Ecology 76:26172626.

LAURANCE, W. F. 2004. Forest-climate interactions in fragmented tropical landscapes. Philosophical Transactions of the Royal Society, series B Biological Sciences 359:345-352.

MCCORMICK, M. K., WHIGHAM, D. F., SLOAN, D., O'MALLEY, K. \& HODKINSON, B. 2006. Orchid-fungus fidelity: a marriage meant to last? Ecology 87:903-911.

MURASHIGE, T. \& SKOOG, F. 1962. A revised medium for rapid growth and bioassays with tobacco tissue cultures. Plant Physiology 15:473497.

NADKARNI, N. M. \& SOLANO, R. 2002. Potential effects of climate change on canopy communities in a tropical cloud forest: an experimental approach. Oecologia 131:580-586.

PEARSON, T. R. H., BURSLEM, D. F. R. P., GOERIZ, R. E. \& DALLING, J. W. 2003. Regeneration niche partitioning in neotropical pioneers: effects of gap size, seasonal drought and herbivory on growth and survival. Oecologia 137:456-465.

PERFECTO, I., RICE, R. A., GREENBERG, R. \& VANDERVOORT, M. E. 1996. Shade coffee: a disappearing refuge for biodiversity. BioScience 46:598-608.

PYPKER, T. G., UNSWORTH, M. H. \& BOND, B. J. 2006. The role of epiphytes in rainfall interception by forests in the Pacific Northwest. II. Field measurements at the branch and canopy scale. Canadian Journal of Forest Research 36:819-832.

SHEIL, D., BURSLEM, D. F. R. P. \& ALDER, D. 1995. The interpretation and misinterpretation of mortality rate measures. Journal of Ecology 83:331-333.

SOLIS-MONTERO, L., FLORES-PALACIOS, A. \& CRUZ-ANGÓN, A. 2005. Shade-coffee plantations as refuges for tropical wild orchids in central Veracruz, Mexico. Conservation Biology 19:908-916.

SOSA, V.\& PLATAS, T. 1998. Extinction and persistence of rare orchids in Veracruz, Mexico. Conservation Biology 12:451-455. 
TREMBLAY, R. L., ZIMMERMAN, J. K., LEBRÓN, L., BAYMAN, P., SASTRE, I., AXELROD, F. \& ALERS-GARCÍA, J. 1998. Host specificity and low reproductive success in the rare endemic Puerto Rican orchid Lepanthes caritensis. Biological Conservation 85:297-304.

WERNER, F. \& GRADSTEIN, S. 2008. Seedling establishment of vascular epiphytes on isolated and enclosed forest trees in an Andean landscape, Ecuador. Biodiversity and Conservation 17:3195-3207.

WINKLER, M. 2005. Population dynamics of epiphytes related to canopy structure in a Mexican humid montane forest. Dr.sc. Thesis, Universität für Bodenkultur, Vienna, Austria.

WINKLER, M. \& HIETZ, P. 2001. Population structure of three epiphytic orchids (Lycaste aromatica, Jacquiniella leucomelana and J. teretifolia) in a Mexican humid montane forest. Selbyana 22:27-33.
WINKLER, M., HÜLBER, K. \& HIETZ, P. 2005. Effect of canopy position on germination and seedling survival of epiphytic bromeliads in a Mexican humid montane forest. Annals of Botany 95:1039-1047.

ZOTZ, G. 2007. Johansson revisited: the spatial structure of epiphyte assemblages. Journal of Vegetation Science 18:123-130.

ZOTZ, G. \& HIETZ, P. 2001. The physiological ecology of vascular epiphytes: current knowledge, open questions. Journal of Experimental Botany 52:2067-2078.

ZOTZ, G. \& VOLLRATH, B. 2002. Substrate preferences of epiphytic bromeliads: an experimental approach. Acta Oecologica 23:99-102.

ZOTZ, G., HIETZ, P. \& SCHMIDT, G. 2001. Small plants, large plants: the importance of plant size for the physiological ecology of vascular epiphytes. Journal of Experimental Botany 52:2051-2056. 